\title{
Two-dimensional electrophoresis protein profiles of HL-60 and CCRF-CEM cell lines treated with epigenetic modification drugs
}

\author{
Aziee Sudin ${ }^{\mathrm{a}}$, Haiyuni Mohd Yassimª, Shafini Mohamed Yusoffa, Shaharum Shamsuddinn ${ }^{\mathrm{b}, \mathrm{c}}$, Ridhwan \\ Abdul Wahab ${ }^{\mathrm{d}}$, Muhammad Farid Johan ${ }^{a^{*}}$ \\ ${ }^{a}$ Department of Haematology, School of Medical Sciences, Universiti Sains Malaysia, 16150 Kubang Kerian, Kelantan, Malaysia \\ ${ }^{b}$ School of Health Sciences, Universiti Sains Malaysia, 16150 Kubang Kerian, Kelantan, Malaysia \\ 'Institute for Research in Molecular Medicine (INFORMM), Universiti Sains Malaysia, 16150 Kubang Kerian, Kelantan, Malaysia \\ ${ }^{d}$ Department of Biomedical Science, Kulliyyah of Allied Health Sciences, International Islamic University Malaysia, Kuantan Campus, 25200 \\ Kuantan, Pahang, Malaysia
}

Received 24th December 2018 / Accepted 24th May 2019

\begin{abstract}
Leukemia is classified as a malignant disease of hematopoietic stem cells (HSCs) that fails in cell differentiation but preserve their self-renewal. It is caused by genetic alterations and epigenetic modifications resulting in the activation or inactivation of particular genes for transcription. Epigenetic causes changes in gene expression without any alteration in the DNA sequence. The most common epigenetic modifications are DNA methylation and histone acetylation. 5-Azacitidine (5-Aza) is a DNA methytransferase inhibitor (DNMTi) that inhibits DNA methyltransferase enzymes resulting in hypomethylation. Trichostatin A (TSA) is a histone deacetylase inhibitor which inhibits deacetylation of both histone and non-histone proteins resulting in chromatin relaxation. This present study focused on the alteration of proteome profile on 2D gel electrophoresis (2-DE) induced by 5-Aza and TSA in HL-60 and CCRF-CEM cell lines as in vitro model to represent acute promyelocytic leukemia (APL) and Tlymphoblastic leukemia (T-ALL), respectively. Total proteins of untreated and 5-Aza/TSA-treated HL-60 and CCRF-CEM cell lines were extracted using urea/thiourea buffer and stained with Coomassie Blue. Comparative analysis of untreated and 5-Aza/TSA-treated HL-60 and CCRF-CEM was performed by PDQuest software. Qualitative analysis identified 190-659 protein spots detected in untreated, 5-Aza and TSA-treated HL-60 and CCRF-CEM. Quantitative comparison analysis was analyzed by over 2-fold change in 5-Aza/TSA-treated cells compared to untreated. One and eight upregulated proteins were detected in 5-Aza and TSA-treated HL-60, respectively. While five and one upregulated proteins were detected in 5-Aza and TSA-treated CCRF-CEM, respectively. These preliminary results suggested that 5Aza and TSA induced proteome profiles alterations due to their inhibition effects in HL-60 and CCRFCEM cell lines.
\end{abstract}

Keywords: Epigenetic, 2-DE, 5-Aza, TSA, HL-60, CCRF-CEM

\section{INTRODUCTION}

Leukemia is a type of blood cancer due to the accumulation of malignant hematopoietic stem cells (HSCs) that is lost in cell differentiation but preserve their self-renewal result in bone marrow failure and tissue infiltration (Luczak et al., 2012b; Qureshi and Hall, 2013). Leukemia arises from

*Author for correspondence: Associate Professor Dr. Muhammad Farid Johan, Department of Haematology, School of Medical Sciences, Universiti Sains Malaysia, 16150 Kubang Kerian, Kelantan, Malaysia. Email faridjohan@usm.my 
lymphocytes, myeloid cells, erythrocytes, and others in the bone marrow, lymph nodes or spleen. Regardless of the cell type origin, the course of leukemia is either acute; aggressively progressing or chronic; slowly progressing (Ntziachristos et al., 2013).

Acute promyelocytic leukemia (APL) is a distinct subtype of acute myeloid leukemia (AML), categorized as APL with $\mathrm{t}(15 ; 17)$ (q22;q11-12), promyelocytic leukemiaretinoic acid receptor alpha (PML-RARA) by World Health Organization (WHO) and AMLM3 in French-American-British (FAB) classification system (Estey, 2015; Karim et al., 2014). It is categorized by abnormal overgrowth of immature granulocytes (promyelocytes) (Wang et al., 2014). Previous study reported that the annual incidence rate of APL was 0.08 cases per 100000 population and 5-8\% of AML cases in younger patients (Arber et al., 2017). Coagulopathy occurs in most APL patients and it is life-threatening (Breen et al., 2012).

T-lymphoblastic leukemia (T-ALL) is a neoplasm of T-lymphocytes (lymphoblasts) by WHO. T-ALL presents as a tissue-based mass of thymus, swollen lymph nodes or extranodal sites (You et al., 2015). T-ALL patients have abnormal karyotype and the most frequent cytogenetic abnormality are translocations of alpha and delta T-cell receptor loci at $14 \mathrm{q} 11.2$, the beta locus at $7 \mathrm{q} 35$, or the gamma locus at 7p14-15 (Taylor and Wang, 2012). Previous study reported that T-ALL comprises of $15 \%$ among childhood acute lymphoblastic leukemia (ALL) and 25\% among adult ALL cases (Borowitz et al., 2017).

Genetic alterations such as deletion, mutations or chromosomal translocations lead to leukemia. Epigenetic is another molecular mechanism that also promotes leukemia initiation by silencing tumor suppressor genes (Ahuja et al., 2016). Epigenetic causes changes in gene expression that do not change the DNA sequence (Stahl et al., 2016). The most common epigenetic modifications involve DNA methylation and histone acetylation (Deng et al., 2016; Matoušová et al., 2014). DNA methylation is an addition of methyl group to the 5-carbon position of cytosine by DNA methyltransferases (DNMTs) resulting in 5-methylcytosine (Wouters and Delwel, 2016). Histone acetylation involves the transfer of acetyl to lysine residues in histone proteins. Histone acetyltransferase (HAT) transfers acetyl whereas histone deacetylase (HDAC) removes acetyl from histone (West and Johnstone, 2014).

Hypermethylation due to aberrant DNA methylation of promoter region resulting in silencing of tumor suppressor genes and transcription inactivation have been shown in all stages of cancer (Huang et al., 2011; Matoušová et al., 2014). Unbalanced activity of HAT and HDAC such as over expression of HDAC lead to chromatin condensation and inactivation of tumor-suppressor genes in cancer cells (Deng et al., 2016). Unlike genetic alterations, epigenetic is reversible and the modifications of affected genes could be recovered and re-programmed to normal state (Ahuja et al., 2016).

5 -Aza was first synthesized almost 40 years ago by Piskala and Sorm (Christman, 2002). 5-Aza inhibits DNMT1, DNMT3A and DNMT3B to result in DNA hypomethylation and re-activation of silencing tumor suppressor genes (Wongtrakoongate, 2015). 5-Aza has been approved for the treatment of myelodysplastic syndrome (MDS) and acute myeloid leukemia (AML) with low blast count by the US Food and Drug Administration (FDA) (Wouters and Delwel, 2016). 5-Aza showed positive effect by reexpressing Gata2 in Tet2-null mice with FLT3ITD mutation to produce cell differentiation (Shih et al., 2015).

TSA, a hydroxamate acid-based pan-HDACi, previously identified as an anti-fungal agent derived from metabolites of strains Streptomyces bygroscopius (Tsuji et al., 1976), was used in clinical trials to inhibit HDACs class I and II for hematological malignancies (Spiegel et al., 2012). TSA inhibits HDAC activity and increases accumulation of histone acetylation by releasing acetic acid from acetylated histone (Bantscheff et al., 2011). Previous studies reported that TSA induced less HDAC9 expression in AML blasts and cell lines (Bradbury et al., 2005). The epigenetic modification drugs such as 5-Aza and TSA specifically target to reactivate the silencing of tumor suppressor genes resulted in cell differentiation and apoptosis (Fard et al., 2012; Hollenbach et al., 2010; Horing et al., 2013; Yu et al., 2008).

The main focus of proteomic study is the proteome, a set of proteins occurring at a given time and a given place in an organism. Proteomic 
analysis creates possibility to determine how various diseases affect the pattern of protein accumulation and contribute to the development of treatment strategies (Luczak et al., 2012a). Proteomic analysis provides a detailed overview of differentially expressed proteins in cellular pathways and disease processes (Almaiman $e t$ al., 2016). The differentially expressed proteins provide information on the biochemical changes that may explain the mechanism underlying leukemia progression.

2D gel electrophoresis (2-DE) is a technique to separate complex protein mixtures based on their isoelectric point (first dimension) and molecular weight (second dimension) (Almaiman et al., 2016). Coupled with Coomassie blue staining and image analysis, 2-DE allows for the simultaneous detection and relative quantification of several hundreds of individual proteins (Pallen et al., 2014). It is widely used to study qualitative and quantitative protein changes between different states of a cell (e.g. healthy and diseased), conditionally expressed protein and posttranslational modifications. This technique has its ability for comparative proteomic analysis to screen biomarkers and identification of drug targets (Kumar et al., 2017).

Therefore, in the present study, HL-60 and CCRF-CEM leukemic cell lines representing APL and T-ALL were utilized to evaluate 2-DE proteome profiles alteration between untreated and 5-Aza/TSA-treated environment. The evaluation was performed based on all detectable protein spots corresponding to the different cell groups. Two types of analyzes were conducted: qualitative analysis, referring to the presence or absence of protein spots and quantitative analysis, referring to the optical intensity of protein spots.

\section{MATERIALS AND METHODS}

The culture and treatment of cell lines. CCRFCEM (human T-lymphoblastic leukemia), donated by Integrated Centre for Research Animal Care and Use (ICRACU), International Islamic University Malaysia and HL-60 (human acute promyelocytic leukemia) donated by Faculty of Health Sciences, University of Sultan Zainal Abidin were originally purchased from American
Type Cell Culture (ATCC) (MD, USA). The cell lines were cultured in Roswell Park Memorial Institute (RPMI)-1640 (Gibco, CA, USA) supplemented with 10\% fetal bovine serum (FBS) (Gibco, CA, USA) and $1 \%(\mathrm{v} / \mathrm{v})$ penicillinstreptomycin (Invitrogen, CA, USA) at $37^{\circ} \mathrm{C}$ in a humidified atmosphere air with $5 \% \mathrm{CO}_{2}$. The $\mathrm{IC}_{50}$ of 5-Aza and TSA in HL-60 and CCRF-CEM were established previously (Aziee et al., 2018). HL-60 was treated with 5-Aza at $\mathrm{IC}_{50}(2.01 \mu \mathrm{M})$ and TSA at $\mathrm{IC}_{50}(2.35 \mu \mathrm{M})$ for 72 and 48 hours, respectively. CCRF-CEM was treated with 5-Aza at $\mathrm{IC}_{50}(1.98 \mu \mathrm{M})$ and TSA at $\mathrm{IC}_{50}(2.65 \mu \mathrm{M})$ for 72 hours.

Total protein preparation. The total protein of untreated and 5-Aza/TSA-treated HL-60 and CCRF-CEM $\left(10-30\right.$ x $10^{6}$ cells $\left./ \mathrm{ml}\right)$ were homogenized with urea/thiourea buffer $(7 \mathrm{M}$ urea, $2 \mathrm{M}$ thiourea, 1\% ASB-14, 40mM Tris, $0.001 \%$ Bromophenol Blue $200 \mathrm{mM}$ Tributylphospine (TBP) and $0.2 \%$ ampholyte) supplemented with protease inhibitor. Cells were placed on ice and sonicated with an ultrasonic probe (Daihan Scientific Co, Gangwon-do, KR) to disrupt cells and fragment the genomic DNA. The samples were sonicated for 3-4 times or until lysis was completed. The samples were chilled on the ice briefly between each ultrasonic treatment and centrifuged at $16,000 \mathrm{x}$ for $30 \mathrm{mins}$ at $18^{\circ} \mathrm{C}$. The supernatant was transferred to a $1.5 \mathrm{ml}$ centrifuge tube (Eppendorf, NY, USA) and the protein concentration for each cell extract was measured by RC DC protein assay (Bio-Rad Laboratories, CA, USA). The cell extracts were stored at $-80^{\circ} \mathrm{C}$ (Thermos Fisher scientific, MA, USA) for 2-DE.

$2 D$ gel electrophoresis (2-DE). Prior to isoelectric focusing (IEF), $600 \mu \mathrm{g}$ of total protein was dissolved with $1 \%$ of ampholyte (Bio-Rad Laboratories, CA, USA) and rehydrated in passive condition using $7 \mathrm{~cm}$ IPG strip pH 4-7 (Bio-Rad Laboratories, CA, USA). The PROTEAN il2 IEF (Bio-Rad Laboratories, CA, USA) was programmed under $250 \mathrm{~V}$ for 20 mins, $4000 \mathrm{~V}$ for 2 hours, $4000 \mathrm{~V}$ for 14000 Volt-hours and $500 \mathrm{~V}$ for stabilizing to run IPG strip. The IPG strip was equilibrated with equilibration buffer I ( $0.06 \mathrm{~g}$ of $6 \mathrm{M}$ urea, $0.625 \mathrm{~mL}$ of $1.5 \mathrm{M}$ Tris- $\mathrm{HCl}, 0.25 \mathrm{~mL}$ of $20 \%(\mathrm{v} / \mathrm{v})$ SDS solution, $1 \mathrm{~mL}$ of $20 \%$ glycerol, $0.6 \mathrm{~mL}$ of distilled water and $0.025 \mathrm{~mL}$ of $1 \%$ 
(w/v) dithiothretol) for 10 mins and equilibration buffer II $(0.06 \mathrm{~g}$ of $6 \mathrm{M}$ urea, $0.625 \mathrm{~mL}$ of $1.5 \mathrm{M}$ Tris-HCl, $0.25 \mathrm{~mL}$ of $20 \%$ (v/v) SDS solution, 1 $\mathrm{mL}$ of $20 \%(\mathrm{v} / \mathrm{v})$ glycerol, $0.6 \mathrm{~mL}$ of distilled water and $0.025 \mathrm{~mL}$ of $2 \%(\mathrm{v} / \mathrm{v})$ iodoacetamide) for 10 mins at room temperature with gentle shaking. Electrophoresis was run at a constant volt of $90 \mathrm{~V}$ for 1 hour and 50 mins in a MiniPROTEAN tetra cell (Bio-Rad Laboratories, CA, USA). After gel electrophoresis completed, the gel was stained with Coomassie blue (Bio-Rad Laboratories, CA, USA) for one hour.

Image analysis. The gel image was captured using GS-800 Calibrated densitometer (Bio-Rad Laboratories, CA, USA). Scanned 2-DE gel images were analyzed with PDQuest software (Bio-Rad Laboratories, CA, USA). The spots detection was based on spots intensities. Briefly, any artifacts (speckles) on 2-DE gel images were removed by setting the minimum spot diameter to a level greater than the diameter of the speckles. The process of detecting spots was automated and required significant input parameters (spot size; light, small and large) in order to register the spots correctly. PDQuest software applied these parameters to detect majority of protein spots on 2-DE gel image and several protein spots were manually defined (e.g. adding or removing spots). A match set was created for comparison analysis to match the corresponding spots across gels according to the master gel (selected based in good spot quality). Automatic matching was performed to highlight similarities and differences for quantitative comparison. Each 2-DE gel image was normalized to reduce variability in terms of protein load per gel, staining efficiency or image capture. All comparative analyses were statistically analyzed.

\section{RESULTS AND DISCUSSION}

\section{2-DE proteome profiles of HL-60 and CCRF-}

$\boldsymbol{C E M}$. Figures 1 and 2 showed representative 2DE protein profiles of untreated, 5-Aza- and TSA-treated HL-60 and CCRF-CEM. Table 1 and 2 demonstrated qualitative analysis of protein spots detected in each gel of untreated, 5-Aza- and TSA-treated HL-60 and CCRF-CEM. 2-DE gel images were analyzed in duplicate to minimize gel-to-gel variation. Protein spots were reproducible as both cell groups have a close matching rate.

Table 1. Qualitative analyzes of protein spots detected of untreated, 5-Aza and TSA-treated HL-60.

\begin{tabular}{cccccccc}
\hline \multicolumn{2}{c}{ HL-60 } & Gel 1 & Gel 2 & Gel 3 & $\begin{array}{c}\text { Reproducible } \\
\text { spots }\end{array}$ & $\begin{array}{c}\text { Matching } \\
\text { rate }^{\mathbf{a}} \mathbf{( \% )}\end{array}$ & $\begin{array}{c}\text { Correlation } \\
\text { coefficient }\end{array}$ \\
\hline \multirow{2}{*}{ Untreated } & Extract 1 & 483 & 545 & 501 & \multirow{2}{*}{117} & 69 & 0.628 \\
& Extract 2 & 519 & 562 & 521 & & 72 & 0.632 \\
\hline 5-Aza- & Extract 1 & 620 & 642 & 601 & \multirow{2}{*}{392} & 89 & 0.729 \\
treated & Extract 2 & 557 & 659 & 613 & & 79 & 0.729 \\
\hline \multirow{2}{*}{ TSA-treated } & Extract 1 & 352 & 350 & 349 & \multirow{2}{*}{190} & 86 & 0.626 \\
& Extract 2 & 490 & 468 & 505 & & 77 & 0.774 \\
\hline
\end{tabular}

aMatching rate represents the percentage of matched spots on the gel relative to the total number of spots on the master gel.

Table 2. Qualitative analyzes of protein spots detected of untreated, 5-Aza and TSA-treated CCRF-CEM.

\begin{tabular}{cccccccc}
\hline \multicolumn{2}{c}{ CCRF-CEM } & Gel 1 & Gel 2 & Gel 3 & $\begin{array}{c}\text { Reproducible } \\
\text { spots }\end{array}$ & $\begin{array}{c}\text { Matching } \\
\text { rate }^{\mathbf{a}} \mathbf{( \% )}\end{array}$ & $\begin{array}{c}\text { Correlation } \\
\text { coefficient }\end{array}$ \\
\hline \multirow{2}{*}{ Untreated } & Extract 1 & 257 & 217 & 318 & \multirow{2}{*}{231} & 77 & 0.727 \\
& Extract 2 & 319 & 414 & 385 & & 75 & 0.759 \\
\hline 5-Aza- & Extract 1 & 190 & 359 & 305 & \multirow{2}{*}{271} & 64 & 0.727 \\
treated & Extract 2 & 378 & 185 & 255 & & 60 & 0.773 \\
\hline \multirow{2}{*}{ TSA-treated } & Extract 1 & 377 & 194 & 410 & \multirow{2}{*}{105} & 48 & 0.625 \\
& Extract 2 & 347 & 334 & 348 & & 61 & 0.728 \\
\hline
\end{tabular}

a Matching rate represents the percentage of matched spots on the gel relative to the total number of spots on the master gel. 


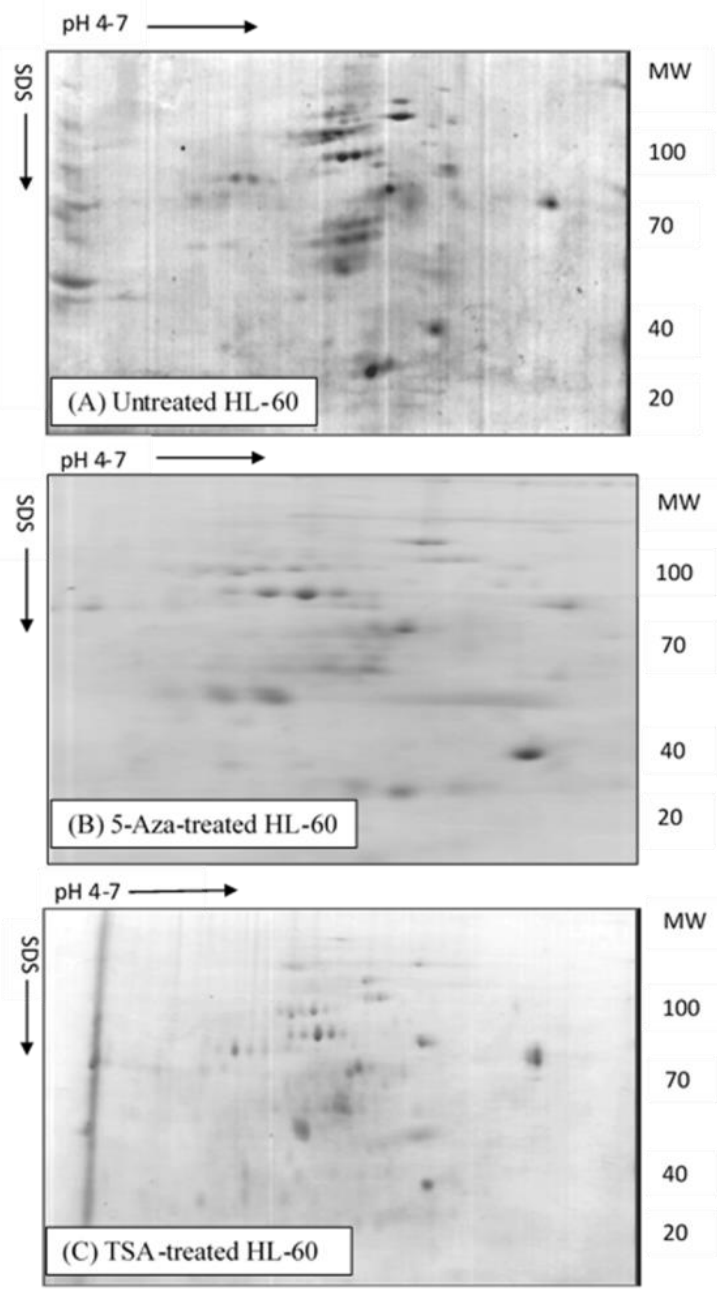

Figure 1. 2-DE gel images of protein from HL60. (A) Untreated, (B) 5-Aza-treated, and (C) TSA-treated. SDS $=2^{\text {nd }}$ Dimension Separation, MW $=$ Molecular weight.

\section{Comparative 2-DE proteome profiles} between untreated and treated HL-60. Quantitative comparison of 2-DE protein profiles between untreated and 5-Aza/TSA-treated HL60 and CCRF-CEM were analyzed to detect differential expressed proteins. Corresponding protein spots were identified (labelled by SSP) based on intensities whose volume changed across different groups (i.e. untreated and 5Aza/TSA-treated). Upregulated proteins were represented with high spot intensity in 5Aza/TSA-treated but low spot intensity in untreated 2-DE gel images, and vice versa for downregulated proteins. Differential expressed proteins were manually checked to confirm their presence or absence in each individual 2-DE gel images.
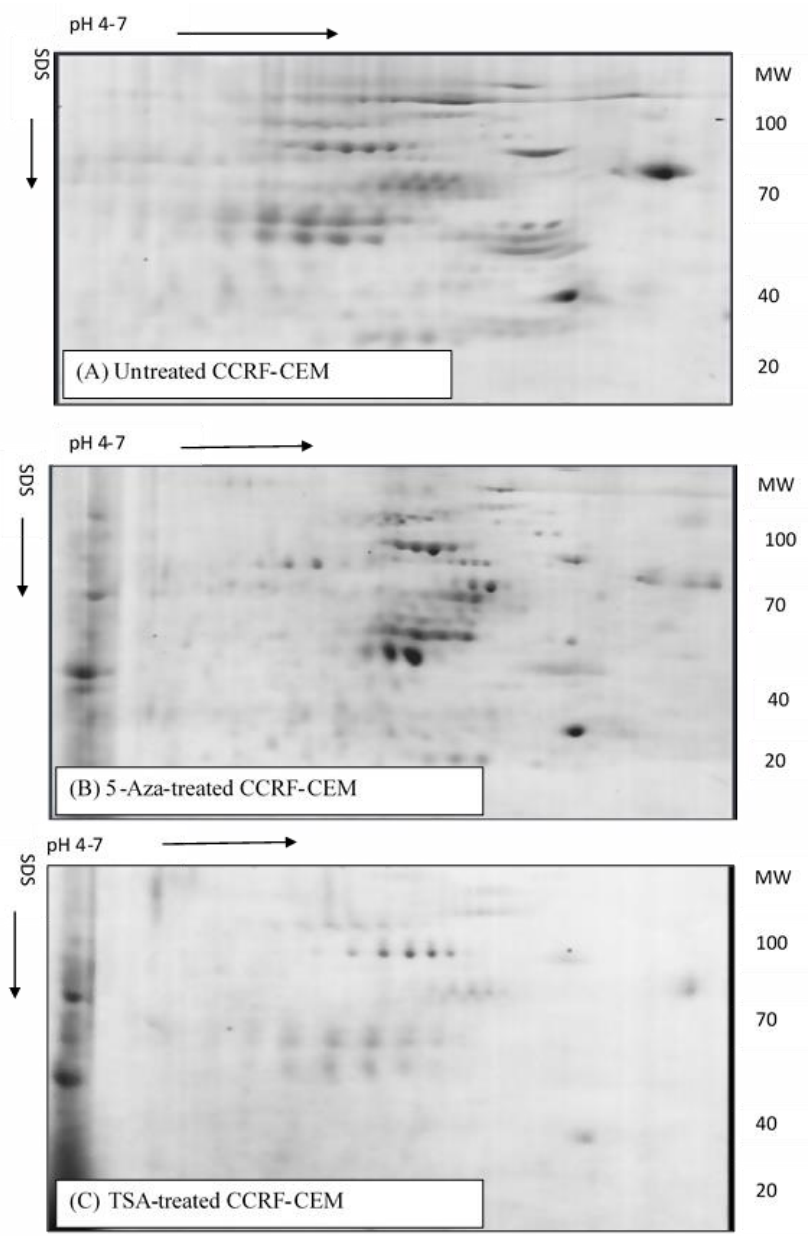

Figure 2. 2-DE gel images of protein from CCRF-CEM (A) Untreated, (B) 5-Aza-treated and (C) TSA-treated. SDS $=2^{\text {nd }}$ Dimension Separation, $\mathrm{MW}=$ Molecular weight.

Table 3 demonstrated quantitative analysis of proteome profiles between untreated and 5Aza/TSA-treated HL- 60 by 2 -fold change. The comparative analyses demonstrated 76 of differential expressed proteins were detected between untreated and 5-Aza-treated HL-60 made up of 45 upregulated and 31 downregulated protein spots. Whereas, 95 of differential expressed proteins were detected between untreated and TSA-treated HL-60 made up of 25 upregulated and 70 downregulated protein spots. Figures 3 and 4 showed representatives of $2-\mathrm{DE}$ images of upregulated and downregulated proteins between untreated and 5-Aza-/TSAtreated HL-60. Correlation of variation (CV) of $\geq 70 \%$ identified 1 and 8 upregulated protein spots between untreated and 5-Aza/TSA-treated HL-60 (Tables 4 and 5, respectively). 
Table 3. Quantitative analysis of protein spots detected, spots matched, matching rate and mean coefficient of variation in untreated, 5-Aza- and TSA-treated HL-60.

\begin{tabular}{ccccc}
\hline Sample group & $\begin{array}{c}\text { No. of protein } \\
\text { spots detected }\end{array}$ & $\begin{array}{c}\text { No. of protein } \\
\text { spots matched }\end{array}$ & $\begin{array}{c}\text { Matching rate } \\
\mathbf{( \% )}\end{array}$ & $\begin{array}{c}\text { Mean coefficient of } \\
\text { variation (CV) }\end{array}$ \\
\hline Untreated 1 & 506 & 195 & 30 & \\
Untreated 2 & 542 & 162 & 26 & 72.20 \\
Untreated 3 & 514 & 151 & 24 & \\
\hline 5-Aza-treated 1a & 620 & 620 & 100 & 51.47 \\
5-Aza-treated 2 & 642 & 163 & 26 & \\
5-Aza-treated 3 & 603 & 153 & 25 & 75.47 \\
\hline TSA-treated 1 & 490 & 490 & 100 & \\
TSA-treated 2 & 468 & 74 & 14 & \\
TSA-treated 3 & 505 & 83 & 16 & \\
\hline
\end{tabular}

a-Aza-treated 1 and TSA-treated 1 denoted as a master gel (good protein spots intensity) by PDQuest software. bMatching rate represents the relativeness of protein spots on a particular gel correspond spots on the master gel. Independent $t$-test, $(p<0.05)$.

(A) Upregulated

(B) Downregulated

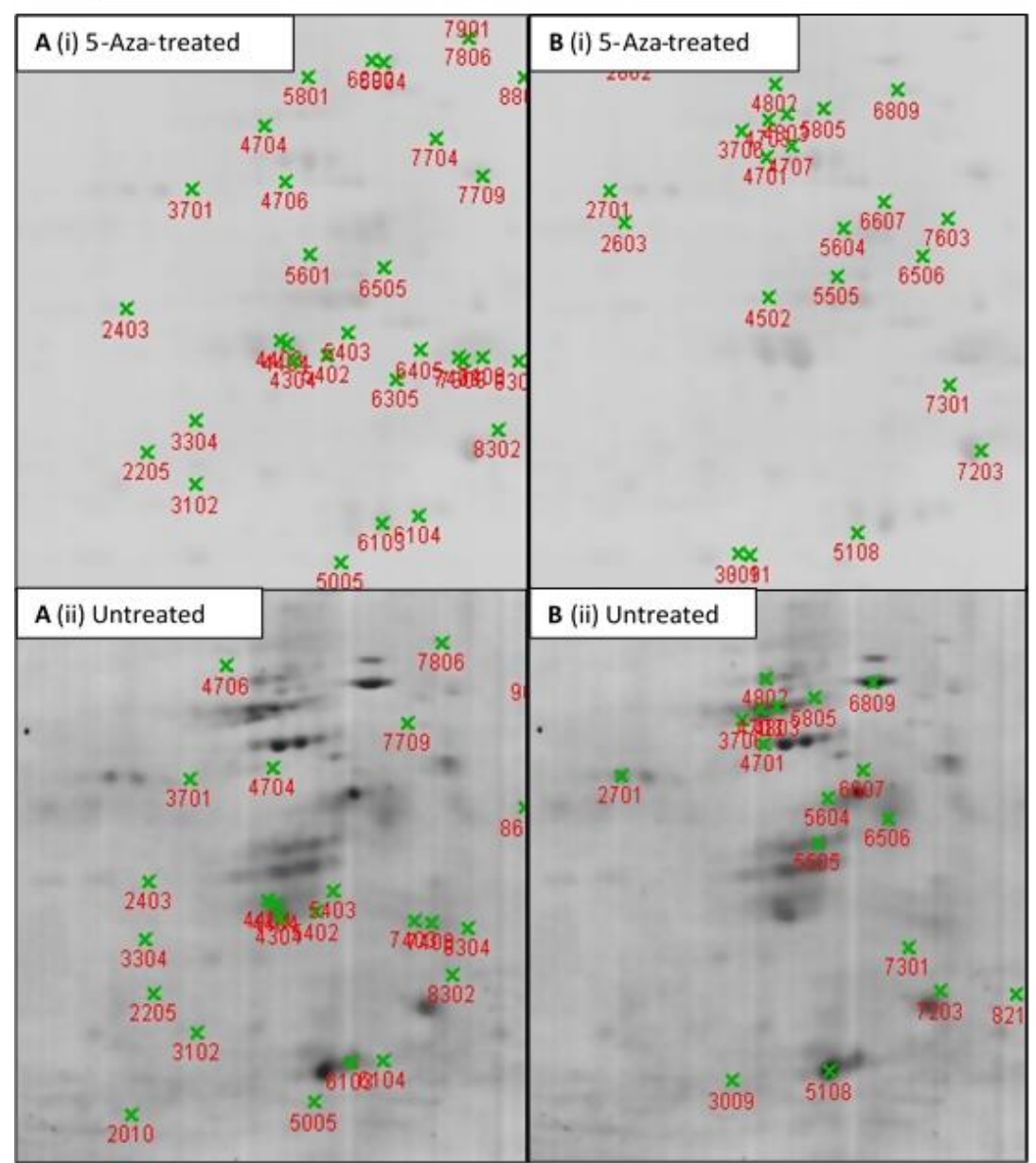

Figure 3. Representative of 2-DE gel images: (A) Upregulated protein spots (i), 5-Aza-treated and (ii), untreated HL-60. (B) Downregulated protein spots (i), 5-Aza-treated and (ii) untreated HL-60. X dots denote the upregulated or downregulated protein spot label with standard spot number (SSP). The same SSP represents the same protein on different gels (Results from PDQuest 2-D analysis software). 
(A) Upregulated

(B) Downregulated

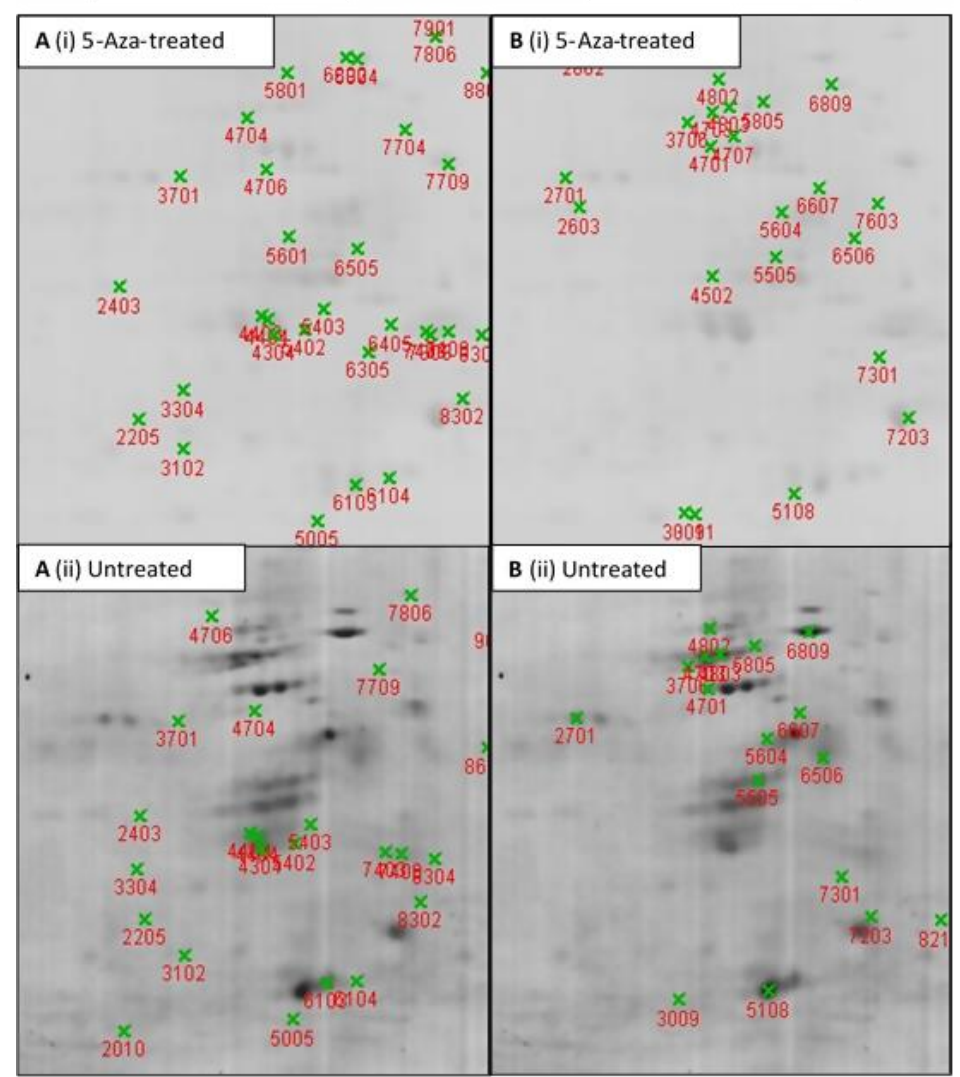

Figure 4. Representative of 2-DE gel images: (A) Upregulated protein spots (i), TSA-treated and (ii), untreated HL-60. (B) Downregulated protein spots (i), TSA-treated and (ii) untreated HL-60. X dots denote the upregulated or downregulated protein spot label with standard spot number (SSP). The same SSP represents the same protein on different gels. (Results from PDQuest 2-D analysis software).

Table 4. List of differential expressed proteins identified by quantitative analysis between untreated and 5-Aza-treated HL-60.

\begin{tabular}{|c|c|c|c|c|c|c|c|}
\hline & \multirow{2}{*}{ SSPa $^{a}$} & \multirow{2}{*}{$\begin{array}{l}\mathrm{MW}^{\mathrm{b}} \\
(\mathrm{kDa})\end{array}$} & \multirow{2}{*}{$\mathrm{pH}^{\mathrm{c}}$} & \multicolumn{2}{|c|}{ Spot intensity $\left(\mathrm{OD}^{\mathrm{d}}\right)$} & \multirow{2}{*}{$\begin{array}{c}\text { Fold } \\
\text { difference } \\
\text { (Relative to } \\
\text { Untreated) } \\
\end{array}$} & \multirow{2}{*}{$\begin{array}{l}\text { CVe } \\
(\%)\end{array}$} \\
\hline & & & & Untreated & $\begin{array}{l}\text { 5-Aza- } \\
\text { treated }\end{array}$ & & \\
\hline \multirow{3}{*}{$\underset{\text { regulated }}{\mathrm{Up}}$} & 3804 & 86.0 & 5.8 & 896.2 & 974.4 & 1.1 & 93.1 \\
\hline & 5701 & 77.4 & 5.6 & 19141.2 & 25401.2 & 1.3 & 77.8 \\
\hline & 6901 & 123.9 & 5.3 & 101.4 & 520.7 & $5.14^{*}$ & 75.7 \\
\hline \multirow{2}{*}{$\begin{array}{l}\text { Down } \\
\text { regulated }\end{array}$} & 5108 & 34.3 & 5.5 & 27548.5 & 2067.3 & 0.1 & 70.9 \\
\hline & 2603 & 67.7 & 6.2 & 5825.5 & 850.1 & 0.2 & 90.4 \\
\hline
\end{tabular}

aSSP - standard spot number denotes the same protein spot on different gels.

bMW - theoretical molecular weight $(\mathrm{kDa})$ obtained from PDQuest software.

$\mathrm{c}$ pl - theoretical isoelectric charge $(\mathrm{pH})$ obtained from PDQuest software.

dOD - optical density measured from the densitometer.

${ }^{\mathrm{e}} \mathrm{CV}$ - correlation of variation must be $\geq 70 \%$; indicates how close of individual gel image match within the replicate group with the same sample and gel electrophoresis.

$* \geq 2$-fold change. 
Table 5. List of differential expressed proteins identified by quantitative analysis between untreated and TSA-treated HL-60.

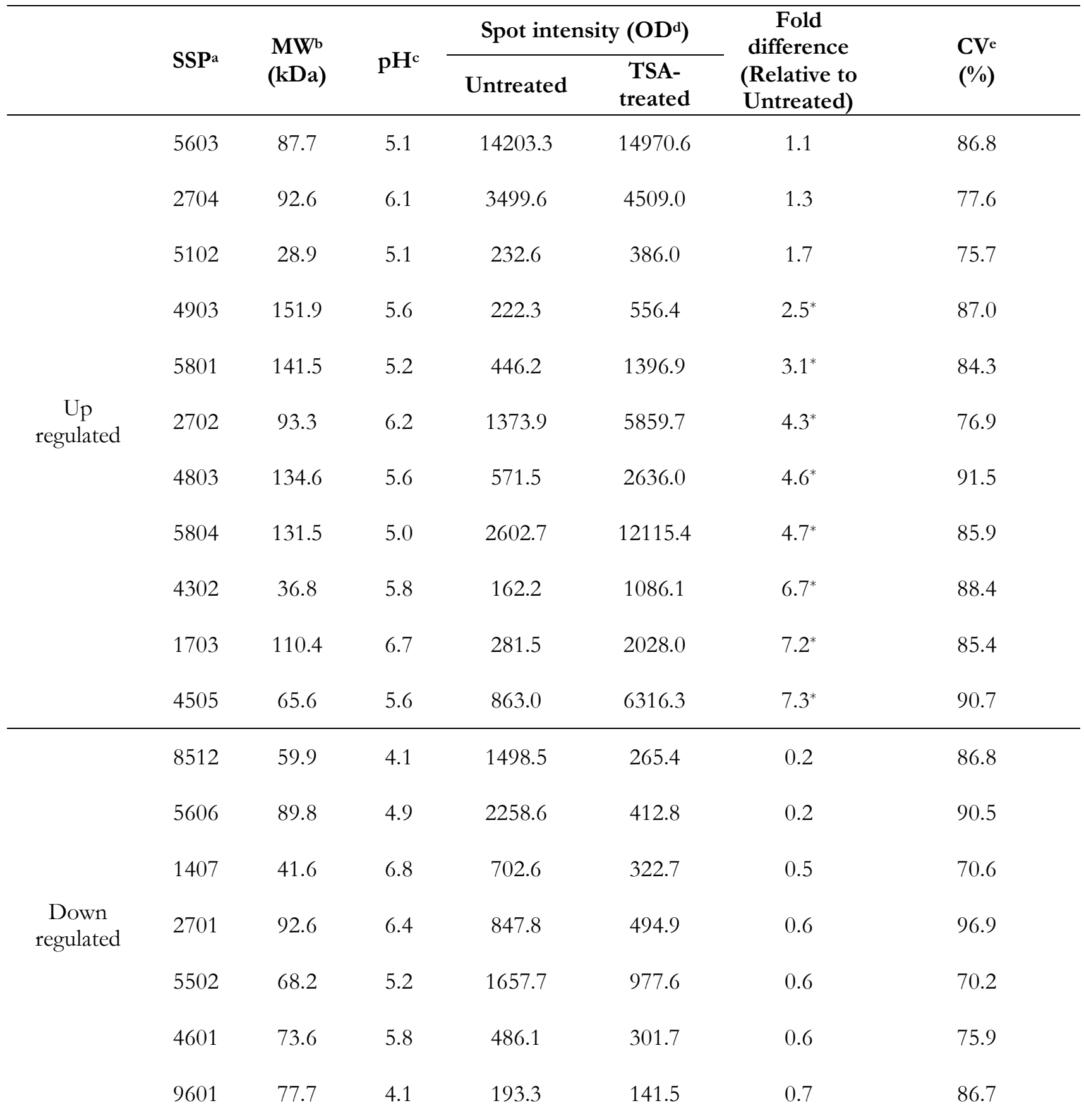

aSSP - standard spot number denotes the same protein spot on different gels.

bMW - theoretical molecular weight $(\mathrm{kDa})$ obtained from PDQuest software.

${ }^{\mathrm{p}} \mathrm{pl}$ - theoretical isoelectric charge $(\mathrm{pH})$ obtained from PDQuest software.

$\mathrm{d} O D$ - optical density measured from the densitometer.

${ }^{\mathrm{e}} \mathrm{CV}$ - correlation of variation must be $\geq 70 \%$; indicates how close of individual gel image match within the replicate group with the same sample and gel electrophoresis.

$* \geq 2$-fold change.

\section{Comparative 2-DE proteome expression} profiles between untreated and treated $\boldsymbol{C C R F - C E M}$. Table 6 represented quantitative analysis of proteome profiles between untreated and 5-Aza/TSA-treated HL-60 by 2 -fold change.
90 differential expressed proteins were detected between untreated and 5-Aza-treated CCRFCEM (32 upregulated and 58 downregulated protein spots). Whereas, 51 differential expressed proteins were detected between untreated and 
TSA-treated CCRF-CEM (22 upregulated and 29 downregulated protein spots). Figures 5 and 6 showed representatives of 2-DE gel images of upregulated and downregulated proteins between untreated and 5-Aza-/TSA-treated
CCRF-CEM. Correlation of variation (CV) of $\geq 70 \%$ identified 5 and 1 upregulated protein spots between untreated and 5-Aza/TSA-treated CCRF-CEM (Tables 7 and 8, respectively).

Table 6. Quantitative analysis of protein spots detected, spots matched, matching rate and mean coefficient of variation in untreated, 5-Aza- and TSA-treated CCRF-CEM.

\begin{tabular}{ccccc}
\hline Sample group & $\begin{array}{c}\text { No. of protein } \\
\text { spots detected }\end{array}$ & $\begin{array}{c}\text { No. of protein } \\
\text { spots matched }\end{array}$ & $\begin{array}{c}\text { Matching rate } \\
\text { (\%) }\end{array}$ & $\begin{array}{c}\text { Mean Coefficient of } \\
\text { variation (CV) }\end{array}$ \\
\hline Untreated 1 & 257 & 74 & 26 & \\
Untreated 2 & 318 & 87 & 31 & 66.39 \\
Untreated 3 & 271 & 86 & 30 & \\
\hline 5-Aza-treated 1 & 283 & 81 & 29 & 74.87 \\
5-Aza-treated 2a & 278 & 278 & 100 & \\
5-Aza-treated 3 & 251 & 82 & 29 & 69.01 \\
\hline TSA-treated 1 & 410 & 56 & 28 & \\
TSA-treated 2a & 194 & 194 & 100 & \\
TSA-treated 3 & 377 & 53 & 27 & \\
\hline
\end{tabular}

a-Aza-treated 1 and TSA-treated 1 denoted as a master gel (good protein spots intensity) by PDQuest software.

bMatching rate represents the relativeness of protein spots on a particular gel correspond spots on the master gel. Independent $t$-test, $(p<0.05)$.

(A) Upregulated

(B) Downregulated

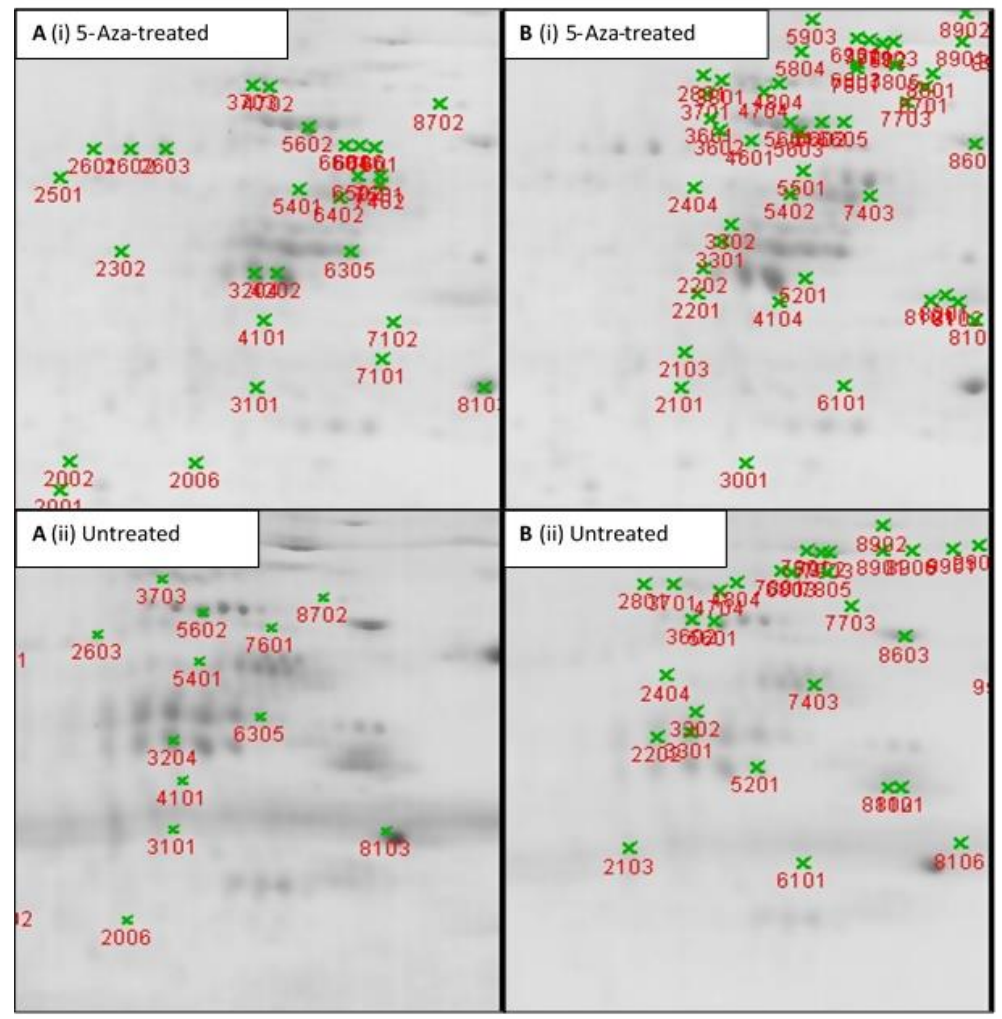

Figure 5. Representative of 2-DE gel images: (A) The upregulated protein spots (i), 5-Aza-treated and (ii), untreated CCRF-CEM. (B) The downregulated protein spots (i), 5-Aza-treated and (ii) untreated CCRFCEM. X dots denote the upregulated or downregulated protein spot label with standard spot number (SSP). The same SSP represents the same protein spot approximately on the same location on different gels. (Results from PDQuest 2-D analysis). 


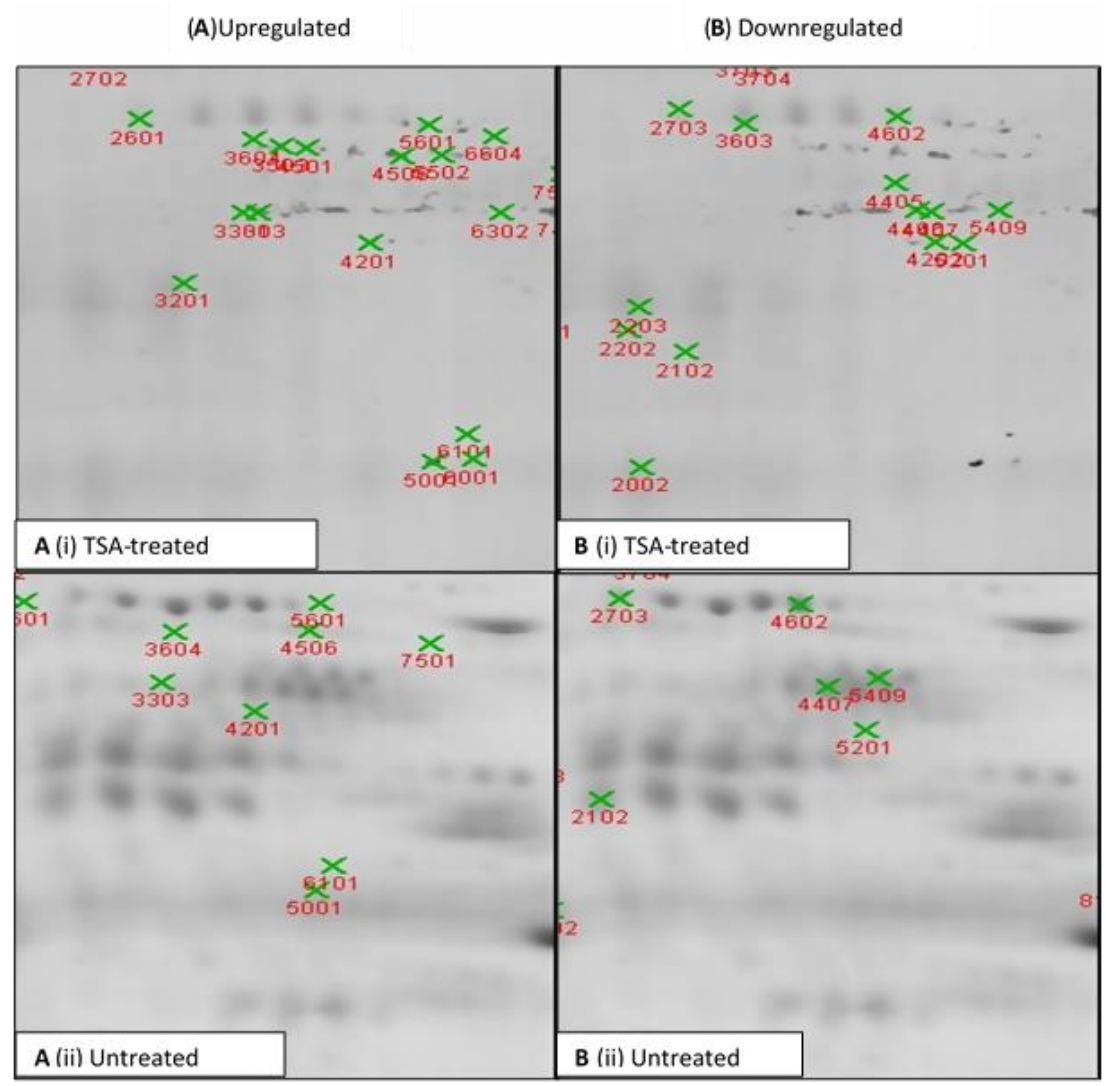

Figure 6. Representative of 2-DE gel images: (A) Upregulated protein spots (i), TSA-treated and (ii), untreated CCRF-CEM. (B) Downregulated protein spots (i), TSA-treated and (ii) untreated CCRF-CEM. $\mathrm{X}$ dots denote the upregulated or downregulated protein spot label with standard spot number (SSP). The same SSP represents the same protein on different gels. (Results from PDQuest 2-D analysis software).

Table 7. List of differential expressed proteins identified by quantitative analysis between untreated and 5-Aza-treated CCRF-CEM.

\begin{tabular}{|c|c|c|c|c|c|c|c|}
\hline & \multirow{2}{*}{ SSPa } & \multirow{2}{*}{$\begin{array}{l}M W^{b} \\
(k D a)\end{array}$} & \multirow{2}{*}{$\mathrm{pl}^{\mathrm{c}}$} & \multicolumn{2}{|c|}{ Spot intensity $\left(\mathrm{OD}^{\mathrm{d}}\right)$} & \multirow{2}{*}{$\begin{array}{c}\text { Fold } \\
\text { difference } \\
\text { (Relative to } \\
\text { Untreated) }\end{array}$} & \multirow{2}{*}{$\begin{array}{l}\mathrm{CV}^{\mathrm{e}} \\
(\%)\end{array}$} \\
\hline & & & & Untreated & $\begin{array}{l}\text { 5-Aza- } \\
\text { treated }\end{array}$ & & \\
\hline \multirow{6}{*}{$\begin{array}{l}\mathrm{Up} \\
\text { regulated }\end{array}$} & 4602 & 95.4 & 6.1 & 5997.1 & 6461.3 & 1.1 & 75.1 \\
\hline & 6502 & 77.6 & 5.9 & 1853.6 & 3756.2 & $2.0^{*}$ & 71.3 \\
\hline & 6604 & 87.1 & 5.9 & 1359.2 & 3415.6 & $2.5^{*}$ & 86.5 \\
\hline & 3101 & 35.7 & 6.1 & 266.6 & 1230.0 & $4.6^{*}$ & 94.4 \\
\hline & 2603 & 86.0 & 6.4 & 792.8 & 4276.7 & $5.4^{*}$ & 82.4 \\
\hline & 6305 & 57.7 & 5.9 & 3018.5 & 18592.4 & $6.2^{*}$ & 94.6 \\
\hline \multirow{5}{*}{$\begin{array}{l}\text { Down } \\
\text { regulated }\end{array}$} & 2201 & 49.3 & 6.25 & 15567.5 & 422.8 & 0.1 & 91.8 \\
\hline & 8902 & 145.1 & 5.19 & 6487.3 & 1340.1 & 0.2 & 74.6 \\
\hline & 1005 & 31.9 & 6.70 & 2049.8 & 1497.7 & 0.7 & 82.4 \\
\hline & 7302 & 67.4 & 5.60 & 2524.4 & 1896.4 & 0.8 & 75.7 \\
\hline & 2402 & 73.0 & 6.31 & 663.8 & 619.9 & 0.9 & 95.8 \\
\hline
\end{tabular}

aSSP - standard spot number denotes the same protein spot on different gels.

bMW - theoretical molecular weight $(\mathrm{kDa})$ obtained from PDQuest software.

${ }^{c} \mathrm{pl}$ - theoretical isoelectric charge $(\mathrm{pH})$ obtained from PDQuest software.

dOD - optical density measured from the densitometer.

${ }^{\mathrm{e}} \mathrm{CV}$ - correlation of variation must be $\geq 70 \%$; indicates how close of individual gel image match within the replicate group with the same sample and gel electrophoresis.

$* \geq 2$-fold change. 
Table 8. List of differential expressed proteins identified by quantitative analysis between untreated and TSA-treated CCRF-CEM.

\begin{tabular}{|c|c|c|c|c|c|c|c|}
\hline & \multirow{2}{*}{ SSPa } & \multirow{2}{*}{$\begin{array}{l}\mathrm{MW}^{\mathrm{b}} \\
(\mathrm{kDa})\end{array}$} & \multirow{2}{*}{$\mathrm{pl}^{\mathrm{c}}$} & \multicolumn{2}{|c|}{ Spot intensity $\left(O D^{d}\right)$} & \multirow{2}{*}{$\begin{array}{c}\text { Fold } \\
\text { difference } \\
\text { (Relative to } \\
\text { Untreated) }\end{array}$} & \multirow{2}{*}{$\begin{array}{l}C{ }^{e} \\
(\%)\end{array}$} \\
\hline & & & & Untreated & $\begin{array}{l}\text { TSA- } \\
\text { treated }\end{array}$ & & \\
\hline \multirow{2}{*}{$\underset{\text { regulated }}{\mathrm{Up}}$} & 6501 & 82.4 & 5.5 & 960.2 & 1262.4 & 1.3 & 94.8 \\
\hline & 6302 & 69.1 & 5.5 & 416.9 & 1702.8 & $4.1^{*}$ & 85.6 \\
\hline \multirow{3}{*}{$\begin{array}{l}\text { Down } \\
\text { regulated }\end{array}$} & 4407 & 69.4 & 5.7 & 10000.4 & 875.6 & 0.1 & 95.1 \\
\hline & 3302 & 65.7 & 5.9 & 1411.9 & 824.6 & 0.6 & 85.2 \\
\hline & 2204 & 51.6 & 6.1 & 11525.4 & 6952.8 & 0.6 & 80.6 \\
\hline
\end{tabular}

aSSP - standard spot number denotes the same protein spot on different gels.

${ }^{\mathrm{b}} \mathrm{MW}$ - theoretical molecular weight $(\mathrm{kDa})$ obtained from PDQuest software.

${ }^{c} \mathrm{pl}$ - theoretical isoelectric charge $(\mathrm{pH})$ obtained from PDQuest software.

dOD - optical density measured from the densitometer.

${ }^{\mathrm{e}} \mathrm{CV}$ - correlation of variation must be $\geq 70 \%$; indicates how close of individual gel image match within the replicate group with the same sample and gel electrophoresis.

$* \geq 2$-fold change.

\section{DISCUSSION}

Proteomic analysis by 2-DE technique was widely applied for protein screening in cells and tissues derived from healthy and disease state (Anagnostopoulos et al., 2005). HL-60 and CCRFCEM human leukemic cell lines were extensively used as in vitro models in cancer research, for example to investigate anticancer drug action and gene/protein analysis (Fard et al., 2012; Perri et al., 2014; Wang et al., 2014). Both cell lines activated proto-oncogenes that lead to cell immortalization (Drexler et al., 2000; Liu et al., 2014). The main objective of this study was to screen the alteration of proteome profiles of HL-60 and CCRF-CEM cell due to epigenetic treatment by 5-Aza and TSA.

This preliminary 2-DE proteomic analysis consist of total protein expression in leukemia and treatment state. Differential expressed proteins between untreated and 5-Aza/TSA-treated represented their specific cellular biological and regulatory processes including cytogenetic abnormalities and transcriptional activity (eg. upregulated, downregulated or silenced) (Heerboth et al., 2014; Kornblau et al., 2009). 2DE technique has the ability to separate and analyze hundreds of protein spots based on spot counting. It might be concluded that 2-DE technique is a basis for global proteome analysis.
The protein spots separation demonstrated a distinct concentration in untreated and 5Aza/TSA-treated HL-60 and CCRF-CEM using IPG strip pH 4-7. This result was consistent with previous study which reported that cytoplasmic protein profile of mononuclear bone marrow cells has good protein separation using IPG strip $\mathrm{pH}$ 4-7 (Pizzatti et al., 2006). Furthermore, Coomassie blue is estimated to 8-29 $\mathrm{ng}$ of sensitivity staining. This staining was good for low copy number of proteins, reducing background efficiently, environmental friendly and reliable with computer software (Garfin, 2003; Lopez, 2007).

2-DE proteome profiles of untreated, 5-Azaand TSA-treated HL-60 and CCRF-CEM showed $52-79 \%$ of matching rates. The matching rate must be more than $50 \%$ to ensure that the protein spots were highly sensitive to be detected, noise was successfully reduced and maximum number of successfully matched spots were detected across all duplicate gels. Matching rate below 90\% may be caused by discrepancy in term of technical inconsistencies (e.g. isoelectric focusing, gel electrophoresis, staining, alignment and spot detection) and biological factors (e.g. biochemical events, physiologic condition, timing of extra cellular signals receive and concentration of antagonist) (Bland et al., 2006; Pizzatti et al., 2006; Smith et al., 2001).

Majority of protein spots on 2-DE gel images represented a single protein. However, some proteins expressed multiple protein spots due to 
ineffective protein migration or co- and posttranslational modifications (Wang et al., 2003). This causes challenges in quantitative comparison of protein spots. Therefore, to overcome this problem, each individual protein spots was manually visualized to confirm the localization on the gel.

The 2-DE proteome profiles of untreated HL-60 and CCRF-CEM represented total protein activity in metabolic pathways and cellular processes of leukemia progression. Protein expression represented dynamic products encoded; if the changes were associated with disorders or external factors, it represents the phenotype of cancer (Kornblau et al., 2009). Previous study reported that most protein expressions in HL-60 are involved in cell signal transduction, cell growth, apoptosis, protein and energy metabolism (Can'e et al., 2010). On the other hand, most protein expressions in CCRFCEM are involved in signal transduction, transcription factor, DNA- and RNA-binding proteins, translation, signaling, enzymes, regulatory, antigen, carriers, differentiation and receptor activity (Anagnostopoulos et al., 2005).

2-DE proteome profiles of 5-Aza/TSAtreated HL-60 and CCRF-CEM may provide a functional link between the alteration of proteome profiles and epigenetic treatment. 5Aza and TSA induced differential expressed proteins possibly due to their anti-cancer effect. It was previously shown that 5-Aza and TSA effectively inhibited and induced apoptosis in HL60 and CCRF-CEM cell lines (Aziee et al., 2018). Previous studies reported that differential expressed proteins corresponded to the quantity of transcription for cell differentiation and apoptosis in vitro and in vivo (Can'e et al., 2010; Luczak et al., 2012a). Furthermore, it was suggested that differential expressed proteins between leukemia and normal samples function in cell growth, cell metabolism, apoptosis and synthesis (Braoudaki et al., 2013; Hu et al., 2011; Pizzatti et al., 2006).

In the present study, 15 upregulated proteins in 5-Aza/TSA-treated were at least 2-fold change higher than untreated HL-60 and CCRF-CEM (Tables 4, 5, 7, and 8). 2-DE detected a 2-fold change between two samples with an acceptable rate of false positives (below 7\%) (Pallen et al., 2014). This quantitative comparison of 2-DE proteome profiles of untreated and 5-Aza/TSAtreated HL-60 and CCRF-CEM demonstrated distinct changes due to epigenetic treatments. Previous studies suggested that 5-Aza directly inhibit DNMT and cytosine results in cell differentiation and apoptosis, while TSA inhibits HDACs activity leading to cancer cells inhibition (Matoušová et al., 2014; Yoshida et al., 1990).

5-Aza and TSA re-express the silencing of certain proteins represented by upregulation of protein spots intensity. Previous study reported that HDACi treatment in colorectal cancer cells resulted in the upregulation of some proapoptotic genes that play important role in extrinsic and intrinsic apoptotic pathways and downregulation of anti-apoptotic genes (Zhu et al., 2004). The altered proteome profiles may be linked to the response of cells to epigenetic modification drugs. This preliminary study indicates a basis for leukemia prognostic and should have been accompanied by protein database analysis using high-throughput protein identification (e.g. mass spectrometry) to demonstrate structural and conformational characterization of the proteins of interest.

\section{CONCLUSION}

A proteomic method based on 2-DE technique was developed for qualitative and quantitative analysis of HL-60 and CCRF-CEM. 5-Aza and TSA have great potential as anti-cancer effect in HL-60 and CCRF-CEM. Comparative analyses revealed that both epigenetic modification drugs induced different expressed proteins. The differentially expressed proteins discovered in this study may provide an overview to the protein alteration in a variety of cell functions and biological processes which could provide potential information in understanding the progression of leukemia. This preliminary finding is an early stage to provide fundamental information on disease mechanism and potential treatment. 


\section{ACKNOWLEDGEMENTS}

The authors acknowledge Ministry of Higher Education (MOHE) for financial support under Fundamental Research Grant Scheme (FRGS) 203/PPSP/6171164 and PPSP Incentive Postgraduate Studies Development Fund (TIPPS 2017), USM. Appreciation goes to Craniofacial Laboratory, School of Dental Sciences, Molecular Laboratory, Department of Hematology and Central Research Laboratory (CRL), School of Medical Sciences, USM for the facilities.

\section{REFERENCES}

Ahuja, N., Sharma, A. R., \& Baylin, S. B. 2016. Epigenetic therapeutics: a new weapon in the war against cancer. Annual Review of Medicine 67(11): 73-89.

Almaiman, A. A., Abdullah, R., Abdul, A. B., Allauddin, Z., Eid, E. E., \& Saghir, S. A. M. 2016. Proteomic profile of acute myeloid leukaemia: A review update. Tropical Journal of Pharmacentical Research 15(7): 1569-1578.

Anagnostopoulos, A. K., Vougas, K., Kolialexi, A., Mavro, A., Fountoulakis, M., \& Tsangaris, G. T. 2005. The protein profile of the human immature T-cell Line CCRF-CEM. Cancer Genomics \& Proteomics 2(1): 271-300.

Aziee, S., Haiyuni, M., Al-Jamal, H., Shafini, M., Abdul Wahab, R., Shamsuddin, S., \& Johan, M. 2018. Apoptotic Induction in CCRF-CEM and HL-60 Human Leukemic Cell Lines by 5Azacitidine and Trichostatin A. Journal of Biomedical \& Clinical Sciences 3(1): 54-61.

Bantscheff, M., Hopf, C., Savitski, M. M., Dittmann, A., Grandi, P., Michon, A. M., Schlegl, J., Abraham, Y., Becher, I., Bergamini, G., Boesche, M., Delling, M., Dumpelfeld, B., Eberhard, D., Huthmacher, C., Mathieson, T., Poeckel, D., Reader, V., Strunk, K., Sweetman, G., Kruse, U., Neubauer, G., Ramsden, N. G., \& Drewes, G. 2011. Chemoproteomics profiling of HDAC inhibitors reveals selective targeting of HDAC complexes. Nature Biotechnology 29(3): 255-265.

Bland, A. M., D’Eugenio, L. R., Dugan, M. A., Janech, M. G., Almeida, J. S., Zile, M. R., \& Arthur, J. M. 2006. Comparison of variability associated with sample preparation in two-dimensional gel electrophoresis of cardiac tissue. Journal of Biomolecular Techniques 17(3): 195199.

Borowitz, M. J., Chan, J. K. C., Bene, M.-c. \& Arber, D. A. (2017). T-lymphoblastic leukaemia/ lymphoma. In Swerdlow, S. H., Campo, E., Harris, N. L., Jaffe, E. S., Pileri, S. A., Stein, H., \& Thiele, J. (Eds.), WHO Classification of Tumours of Haematopoietic and Lymphoid Tissues 4 ed. pp. 209-2012. Lyon: International Agency for Research on Cancer.

Bradbury, C. A., Khanim, F. L., Hayden, R., Bunce, C. M., White, D. A., Drayson, M. T., Craddock, C., \& Turner, B. M. 2005. Histone deacetylases in acute myeloid leukaemia show a distinctive pattern of expression that changes selectively in response to deacetylase inhibitors. Lenkemia 19(10): 17511759.
Braoudaki, M., Lambrou, G., Vougas, K., Karamolegou, K., Tsangaris, G., \& Tzortzatou-Stathopoulou, F. 2013. protein biomarkers distinguish between high- and low-risk pediatric acute lymphoblastic leukemia in a tissue specific manner. Journal of Hematology Oncology 6(52): 1-20.

Can'e, T., Tan, T., Yanhua, X., Lin, R., Cui, L., Fang, P., Maoyu, L., Pengfei, Z., Hong, Y., \& Zhiqiang, X. 2010. Screening for methylation-silenced genes in acute myeloid leukemia HL-60 cell line by a quantitave proteomic approach. Journal of Central South University of Tecbnology 35(7): 641-648.

Christman, J. K. 2002. 5-Azacytidine and 5-aza-2'-deoxycytidine as inhibitors of DNA methylation: mechanistic studies and their implications for cancer therapy. Oncogene 21(1): 54835495.

Deng, Z., Liu, X., Jin, J., Xu, H., Qian Gao, Wang, Y., \& Zhao, J. 2016. Histone deacetylase inhibitor trichostatin a promotes the apoptosis of osteosarcoma cells through p53 signaling pathway activation. International Journal of Biological Sciences 12(11): 1298-1308.

Drexler, H., Fombonne, S., Matsuo, Y., Hu, Z., Hamaguchi, H., \& Uphoff, C. 2000. p53 alterations in human leukemialymphoma cell lines: in vitroartifact or prerequisite for cell immortalization. Leukemia 14(1): 198-206.

Estey, E. 2015. The Leukemia \& Lymphoma Society, New York, pp. 1-7.

Fard, S. S., Tehrani, M. J., \& Ardekani, M. A. 2012. Prostaglandin E2 induces growth inhibition, apoptosis and differentiation in $\mathrm{T}$ and $\mathrm{B}$ cell-derived acute lymphoblastic leukemia cell lines (CCRF-CEM and Nalm-6). Prostaglandins, Leukotrienes And Essential Fatty Acids 87(1): 17-24.

Garfin, D. E. 2003. Two-dimensional gel electrophoresis: an overview. Trends in Analytical Chemistry 22(5): 263-272.

Heerboth, S., Lapinska, K., Snyder, N., Leary, M., Rollinson, S., \& Sarkar, S. 2014. Use of epigenetic drugs in disease: an overview. Genetics \& Epigenetics 6(3): 9-19.

Hollenbach, P. W., Nguyen, A. N., Brady, H., Williams, M., Ning, Y., Richard, N., Krushel, L., Aukerman, S. L., Heise, C., \& MacBeth, K. J. 2010. A comparison of azacitidine and decitabine activities in acute myeloid leukemia cell lines. Plos One 5(2): 1-10.

Horing, E., Podlech, O., Silkenstedt, B., Rota, I., Alesxandros, , Adamopoulou, E., \& Naumann, U. 2013. The histone deacetylase inhibitor trichostatin a promotes apoptosis and antitumor immunity in glioblastoma cells. Anticancer Research 33(5): 1351-1360.

Hu, J., Lin, M., Liu, T., Li, J., Chen, B., \& Chen, Y. 2011. DIGEbased proteomic analysis identifies nucleophosmin/b23 and nucleolin c23 as over-expressed proteins in relapsed/refractory acute leukemia. Lenkemia Research 35(8): 1087-1092.

Huang, Y. W., Kuo, C. T., Stoner, K., Huang, T. H. Y., \& Wang2, L. S. 2011. An overview of epigenetics and chemoprevention. Febs Letters 585(13): 2129-2136.

Karim, F., Shaikh, U., Adil, S. N., \& Khurshid, M. 2014. Clinical characteristics, outcome and early induction deaths in patients with acute promyelocytic leukaemia: a five-year experience at a tertiary care centre. Singapore Medical Journal 55(8): 443-447.

Kornblau, S. M., Tibes, R., Qiu, Y. H., Chen, W., Kantarjian, H. M., Andreeff, M., Coombes, K. R., \& Mills, G. B. 2009. Functional proteomic profiling of AML predicts response and survival. Blood 113(1): 154-164.

Kumar, M., Singh, R., Meena, A., Patidar, B. S., Prasad, R., Chhabra, S. K., \& Bansal, S. K. 2017. An Improved 2Dimensional Gel Electrophoresis Method for Resolving Human Erythrocyte Membrane Proteins. Proteomics Insights 8. 
Liu, X., Yuan, H., Peres, L., Chen, S., Chen, Z., Zhou, J., \& Zhu, J. 2014. The DNA binding property of PML/RARA but not the integrity of PML nuclear bodies is indispensable for leukemic transformation. Plos One 9(8): 1-6.

Lopez, J. L. 2007. Two-dimensional electrophoresis in proteome expression analysis. Journal of Chromatography B 849(2): 190202.

Luczak, M., Kaźmierczak, M., Lewandowski, K., Hadschuh, L., Komarnicki, M., \& Figlerowicz, M. 2012a. Comparative proteomics in acute myeloid leukemia. Contemporary Oncology 16(2): 95-103.

Luczak, M., Kaźmierczakb, M., Handschuha, L., Lewandowskib, K., Komarnickib, M., \& Figlerowicz, M. 2012b. Comparative proteome analysis of acute myeloid leukemia with and without maturation. Journal of Proteomics 75(18): 5734-5748.

Matoušová, M., Votruba, I., Otmar, M., Tloušt'ová, E., Günterová, J., \& Mertlíková-Kaiserová, H. 2014. 2'-deoxy-5,6-dihydro5-azacytidine - a less toxic alternative of $2^{\prime}$-deoxy-5azacytidine. Epigenetics 6(6): 769-776.

Ntziachristos, P., Mullenders, J., Trimarchi, T., \& Aifantis, I. 2013. Mechanisms of epigenetic regulation of leukemia onset and progression. Advances in immunology 117: 1-30.

Pallen, C., Friry-Santini, C., Herouet-Guicheney, C., \& Capt, A. 2014. Technical variability of 2D gel electrophoresis Application to soybean allergens. Toxicology Reports 1: 734742.

Perri, M., Yap, J. L., Yu, J., Cione, E., Fletcher, S., \& Kane, M. A. 2014. BCL-xL/MCL-1 inhibition and RARgamma antagonism work cooperatively in human HL60 leukemia cells. Experimental Cell Research 327(2): 183-191.

Pizzatti, L., Sa, L. A., de Souza, J. M., Bisch, P. M., \& Abdelhay, E. 2006. Altered protein profile in chronic myeloid leukemia chronic phase identified by a comparative proteomic study. Biocbimica et Biophysica Acta 1764(5): 929-942.

Qureshi, A. K. \& Hall, G. W. 2013. Leukaemias: a review. Paediatrics and Child Health 23(11): 461-466.

Shih, A. H., Jiang, Y., Meydan, C., Shank, K., Pandey, S., Barreyro, L., Antony-Debre, I., Viale, A., Socci, N., Sun, Y., Robertson, A., Cavatore, M., Stanchina, E. d., Hricik, T., Rapaport, F., Woods, B., Wei, C., Hatlen, M., Baljevic, M., Nimer, S. D., Tallman, M., Paietta, E., Cimmino, L., Aifantis, I., Steidl, U., Mason, C., Melnick, A., \& Levine, R. L. 2015. Mutational cooperativity linked to combinatorial epigenetic gain of function in acute myeloid leukemia. Cancer Cell 27(4): 502-515.

Smith, M. A., Bains, S. K., Betts, J. C., Choy, E. H., \& Zanders, E. D. 2001. Use of two-dimensional gel electrophoresis to measure changes in synovial fluid proteins from patients with rheumatoid arthritis treated with antibody to CD4. Clinical and Diagnostic Laboratory Immunology 8(1): 105-111.

Spiegel, S., Milstien, S., \& Grant, S. 2012. Endogenous modulators and pharmacological inhibitors of histone deacetylases in cancer therapy. Oncogene 31(5): 537-551.

Stahl, M., Kohrman, N., Gore, S. D., Kim, T. K., Zeidan, A. M., \& Prebet, T. 2016. Epigenetics in cancer: a hematological perspective. Plos Genetics 12(10): 1-21.

Taylor, K. H. \& Wang, M. X. 2012. DNA methylation in acute leukemia. In Tatarinova, T. (Ed.), DNA methylation - from genomics to technology: InTech.

Tsuji, N., Kobayashi, M., Nagashima, K., Wakisaka, Y., \& Koizumi, K. 1976. A New Antifungal Antibiotic, Trichostatin. The Journal of Antibiotics 29(1): 1-6.

Wang, C., Zhang, Q., Gou, B. D., Zhang, T. L., \& Wang, K. 2014. Differentiation-stimulating potency of differentiated HL60 cells after drug treatment. Biomedicine \& Pharmacotherapy 68(5): 581-588.
Wang, W., Sun, J., Nimtz, M., Deckwer, W. D., \& Zeng, A. P. 2003. Protein identification from two-dimensional gel electrophoresis analysis of klebsiella pneumoniae by combined use of mass spectrometry data and raw genome sequences. Proteome Science 1(6): 1-9.

West, A. C. \& Johnstone, R. W. 2014. New and emerging HDAC inhibitors for cancer treatment. The Journal of Clinical Investigation 124(1): 30-39.

Wongtrakoongate, P. 2015. Epigenetic therapy of cancer stem and progenitor cells by targeting DNA methylation machineries. World Journal of Stem Cells 7(1): 137-148.

Wouters, B. J. \& Delwel, R. 2016. Epigenetics and approaches to targeted epigenetic therapy in acute myeloid leukemia. Blood 127(1): 42-52.

Yoshida, M., Kijima, M., Akita, M., \& Beppu, T. 1990. Potent and specific inhibition of mammalian histone deacetylase both in vivo and in vitro by trichostatin A. The Journal of Biological Chemistry 265(28): 1714-1719.

You, M. J., Medeiros, L. J., \& Hsi, E. D. 2015. T-lymphoblastic leukemia/lymphoma. American Journal of Clinical Pathology 144(3): 411-422.

Yu, W. P., Scott, S. A., \& Dong, W. F. 2008. Induction of ID1 expression and apoptosis by the histone deacetylase inhibitor (trichostatin A) in human acute myeloid leukaemic cells. Cell Proliferation 41(1): 86-97.

Zhu, P., Martin, E., Mengwasser, J., Schlag, P., Janssen, K. P., \& Gottlicher, M. 2004. Induction of HDAC2 expression upon loss of APC in colorectal tumorigenesis. Cancer Cell 5(1): 455-463. 